\title{
CHALLENGES OF SELF-HEALING CONCRETE SCALE-UP AND SITE TRIALS.
}

\author{
MARTINS PILEGIS ${ }^{*}$, ROBERT E. DAVIES ${ }^{\dagger}$, ROBERT J. LARK $^{\dagger}$, DIANE R. GARDNER ${ }^{\dagger}$ \\ AND ANTHONY D. JEFFERSON ${ }^{\dagger}$ \\ ${ }^{*}$ Cardiff University \\ Cardiff, UK \\ e-mail: pilegism@cardiff.ac.uk
}

Key words: Self-healing concrete, Site trials, Scale-up, Shape memory polymers

\begin{abstract}
The Materials for Life (M4L) project, funded by EPSRC, is a collaboration of three UK universities investigating interdisciplinary techniques for self-healing of cementitious materials. These include the encapsulation of healing agents lead by Cambridge University, bacterial healing by Bath University, and the development of vascular flow networks and a shape memory polymer (SMP) based crack closure system for concrete by Cardiff University. These techniques have been tested in a laboratory environment on relatively small scale specimens, from which it was observed that their combined effect produced a greater strength recovery than any one of the individual selfhealing systems alone. The current work of the project is concerned with the scale-up of the techniques and their implementation and evaluation in site trials.

Full-scale concrete structures, comprising wall panels incorporating different combinations of the developed self-healing systems, were built by Costain, an industrial partner of the project. These wall panels have been loaded to induce cracks and then the recovery of the structural and durability parameters of the concrete has been monitored over time. An overview of the M4L site trial setup with a particular focus on the challenges of the scale-up of the SMP system in combination with flow networks is discussed.
\end{abstract}

\section{INTRODUCTION}

It is generally accepted that the development of microcracks in concrete allows the ingress of water, carbon dioxide, chloride ions and other substances. This ingress may subsequently cause carbonation, sulphate related degradation of the concrete and potential corrosion of conventional reinforcement [1]. Such degradation results in the requirement for repair and maintenance of concrete structures to ensure their safety and integrity, that in turn incurs economic and social costs.

Cracking of unmodified concrete is virtually unavoidable and is commonly caused by thermal effects, early-age shrinkage, mechanical loading, freeze-thaw effects or a combination of these actions. However, if these cracks could be reduced in size and sealed or healed after their formation, then the deleterious material ingress and corresponding negative effects could be limited or prevented. This would subsequently lead to more durable, resilient and sustainable concrete structures.

The Materials for Life (M4L) research project, funded by EPSRC, focuses on the investigation of interdisciplinary techniques for self-healing of cementitious materials designed to address the aforementioned issues [2]. The project is a collaboration of three universities - Bath, Cambridge and Cardiff. Initial work was concerned with individual techniques in laboratory condition, whereas the current work concentrates on the scale-up of these techniques for application in site 
conditions and the undertaking of site trials.

\subsection{Self-healing techniques}

Cambridge University is leading the work on encapsulated healing agents with the ultimate goal of acquiring microcapsules that can withstand the concrete mixing process, will rupture upon concrete cracking and will release their cargo into the crack plane subsequently healing the crack. Their initial work showed that the most promising healing agent for encapsulation was sodium silicate solution [3].

Bath University is leading the investigation of microbiologically-induced calciteprecipitation as a means of autonomic selfhealing of concrete. Their initial research efforts covered the identification of calciteprecipitating bacteria and their requirements for encapsulation alongside precursors and nutrients in the concrete matrix [4].

Cardiff University focuses on achieving crack closure in concrete using shape memory polymer (SMP) tendons [5] and the creation of hollow flow networks that can be used as a delivery mechanism for healing agents [6].

These techniques have been investigated at laboratory scale and there is evidence that there is benefit in combining techniques to enhance the healing efficiency, for example, by coupling SMP tendons with flow networks [7].

\subsection{Current work and aims}

Initial laboratory investigations have been completed and current work is concentrated on undertaking site trials that incorporate individual and coupled self-healing techniques. The work activities include the scale-up of the techniques for site application, and the design, construction, testing and monitoring of the site structures, all of which are described briefly in the following sections of this paper.

\section{SITE TRIAL SETUP}

\subsection{Aims}

There were two broad aims for the M4L project site trials. The first was to evaluate the feasibility and challenges of scale-up and implementation of different self-healing techniques in a structure in a site environment during design and construction. The second was to investigate and monitor the effectiveness of the site scale self-healing techniques with respect to structural and durability parameters.

\subsection{Location}

Costain, one of the main industrial partners on the M4L project, is the main contractor on the A465 Heads of the Valleys section 2 project, a $£ 200 \mathrm{M}$ contract to upgrade an $8.1 \mathrm{~km}$ section of road between Gilwern to Brynmawr in South Wales, UK, from single to dual carriageway. The M4L trial structures were located on in a compound adjacent to Costain's site offices. The location of the site is shown in Figure 1.

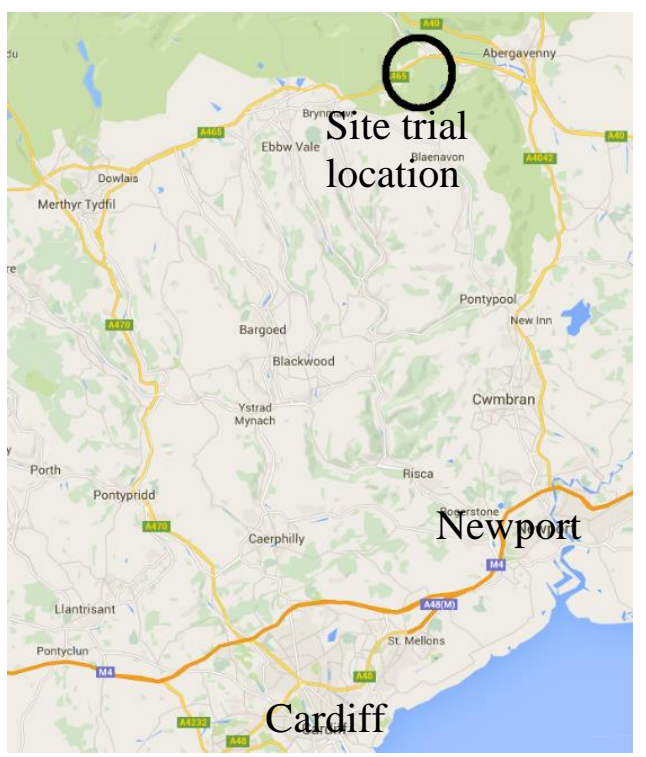

Figure 1: Site trial location

\subsection{Structure design and construction}

The M4L team aimed to replicate a simplified structural element encountered in a construction environment. In this case it was a retaining wall. The design concept, shown in Figure 2, comprised a base, reaction wall and five trial wall panels. The trial panels were 1.8 $\mathrm{m}$ tall, $1 \mathrm{~m}$ wide and $150 \mathrm{~mm}$ thick, the reaction wall was $1.8 \mathrm{~m}$ tall and $200 \mathrm{~mm}$ thick, the concrete base was $400 \mathrm{~mm}$ thick. 


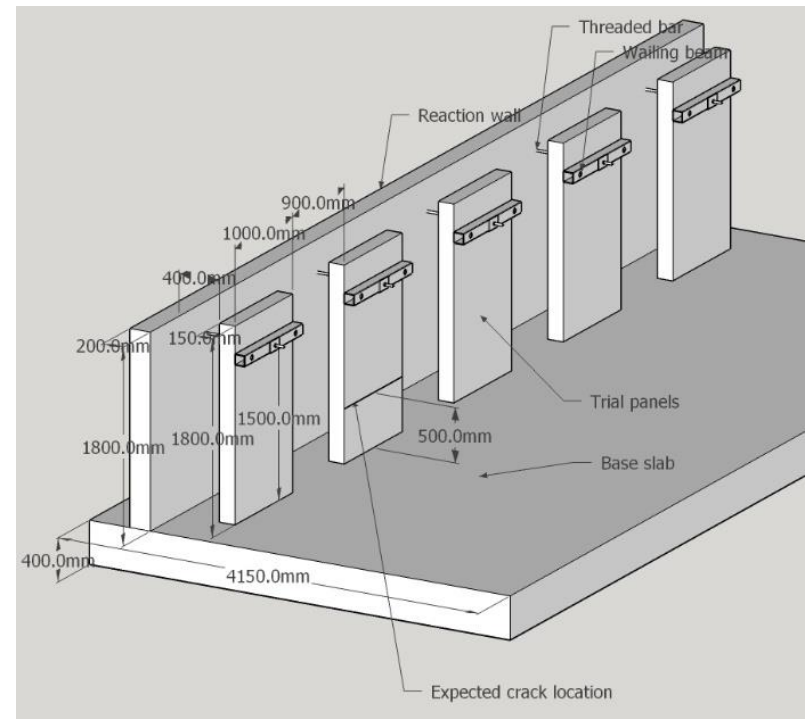

Figure 2: Site trial concept design

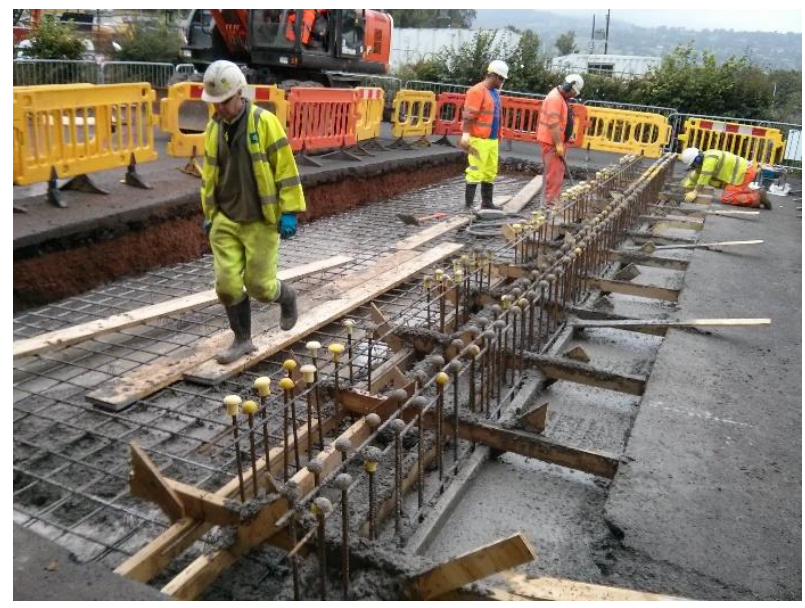

Figure 3: Casting of concrete base slab and kickers

A threaded bar 1.5 metres above the base was passed through both the trial panel and the reaction wall allowing for a jack to be mounted at the back of the reaction wall. A waling beam was attached to the front of the trial panel to distribute the load. A cantilever moment was generated in the trial panel by pulling the threaded bar with a hydraulic jack. This moment induced a crack on the front face of the trial panel $500 \mathrm{~mm}$ above the base where there is a change in the reinforcing steel cross section area. This is the zone in which the self-healing techniques were placed and the monitoring equipment focused in order to evaluate the change in concrete properties.

The trial structure was cast in three stages. Initially the base slab and kickers for the reaction wall and trial panels were cast as shown in Figure 3. After 28 days the reaction wall was cast followed by the trial panels. The trial panel reinforcement and timber formwork are shown in Figure 4. The whole process of all three stages took eight weeks.

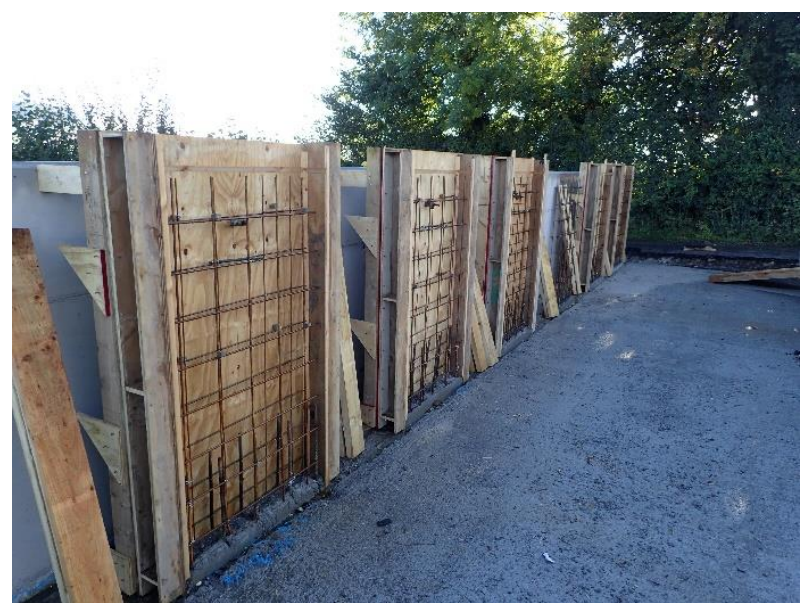

Figure 4: Formwork and reinforcement setup for trial panels

\subsection{Testing and monitoring equipment}

The loading arrangement is shown in Figure 5. It consisted a $200 \mathrm{kN}$ load cell for load monitoring, an access cradle for locking displacement with a nut and a hydraulic jack for load application.

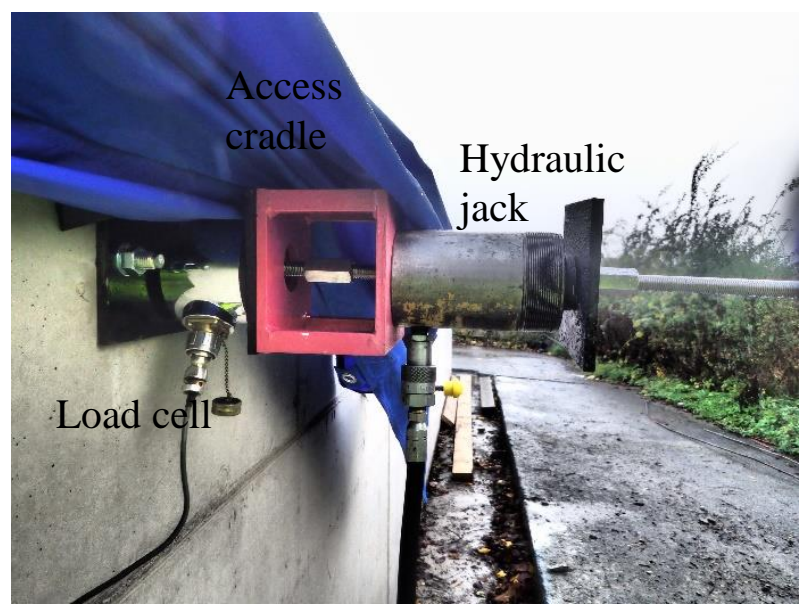

Figure 5: Loading arrangement

The lateral displacements were monitored using six LVDTs per panel. Four of these were mounted on a steel column between the reaction wall and trial panel at the height of load application as shown in Figure 6. Two of them recorded displacements of the reaction wall and the other two that of the trial panel. 
This setup allowed any twist of the panels during the loading to be captured.

The remaining two LVDTs were mounted on the front of the test panel spanning $150 \mathrm{~mm}$ of the expected crack location as can be seen in Figure 7. In order to protect the equipment from weather conditions protective covers were installed and wired connections secured in sealable plastic bags.

The load and displacement data was collected using National Instruments SCXI chassis containing relevant modules.

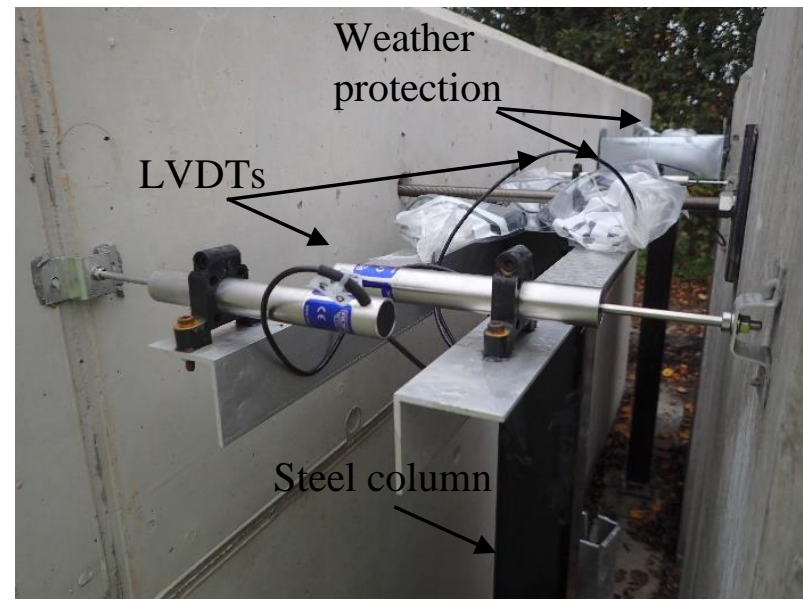

Figure 6: LVDT placement between reaction wall and test panels

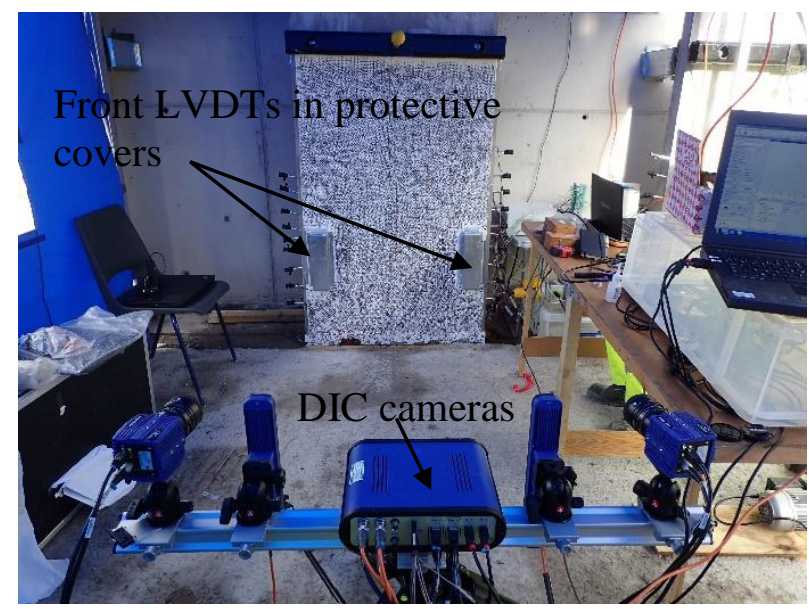

Figure 7: DIC and front LVDT setup

In addition to monitoring using LVDTs, digital image correlation (DIC) equipment was used to record the strains and displacement of the trial panels in three directions during the loading of the structure. This technique required the front face of the test panel to be covered with a speckle pattern as shown in
Figure 7. However, three of the test panels had only half of the front face covered with this pattern to allow permeability measurements to be made along with DIC measurements. The DIC equipment was set up in front of the trial panels as shown in Figure 7.

Localized monitoring of the induced crack was performed using a Veho VMS 004 USB microscope. Images were taken at five locations along the crack and analyzed using Image J which is a public domain Java image processing program.

Another method employed for measuring the strain at the location of the induced crack was demountable mechanical (DEMEC) strain gauge and pips. The pips were attached to the trial panel next to the LVDT cover boxes crossing the expected crack location.

Further measurements were made for changes in air permeability and ultrasonic pulse velocity along the vicinity of the induced crack.

\subsection{Trial panel contents}

The site trials compromised five trial panels in which a base concrete $\mathrm{C} 40 / 50 \mathrm{mix}$, as shown in Table 1 was used.

Table 1: Basic concrete mix design

\begin{tabular}{|c|c|}
\hline Material & $\begin{array}{c}\text { SSD Quantity } \\
\left(\mathrm{kg} / \mathrm{m}^{3} \text { unless }\right. \\
\text { noted otherwise) }\end{array}$ \\
\hline Cement (CEM I) & 415 \\
\hline $\begin{array}{c}\text { 10mm Limestone } \\
\text { aggregates }\end{array}$ & 944 \\
\hline $\begin{array}{l}\text { Limestone fines } \\
(0-2 \mathrm{~mm})\end{array}$ & 396 \\
\hline Marine sand & 393 \\
\hline Water & 179 \\
\hline $\begin{array}{c}\text { Admix: VS100 (SIKA) } \\
\text { plasticiser }\end{array}$ & $\begin{array}{c}0.35 \mathrm{l} / 100 \mathrm{~kg} \\
\text { cement }\end{array}$ \\
\hline $\begin{array}{c}\text { Admix: SIKATARD R } \\
\text { retarder }\end{array}$ & $0.1 \mathrm{l} / 100 \mathrm{~kg}$ cement \\
\hline
\end{tabular}

Two panels were created as controls, whilst the other three contained self-healing techniques developed by the research institutions. The notation of the panel and its contents is given in Table 2 along with any modifications to the basic concrete mix used in 
the particular panel.

More precise details of the contents of all trial panels are outside the scope of this paper, however, a more specific description of Panel $\mathrm{B}$ contents is provided in the following section.

Table 2: Trial panel notation and contents

\begin{tabular}{cc}
\hline Panel & Contents \\
\hline $\mathrm{A}$ & $\begin{array}{c}\text { Microcapsules and basic mix } \\
\text { (microcapsules } 8 \% \text { by weight of } \\
\text { cement) }\end{array}$ \\
\hline $\mathrm{B}$ & $\begin{array}{c}\text { SMP tendons and flow network } \\
\text { with basic mix }\end{array}$ \\
\hline $\mathrm{C}$ & $\begin{array}{c}\text { Encapsulated bacterial spores, } \\
\text { nutrients and flow networks with } \\
\text { equivalent concrete mix }\end{array}$ \\
\hline $\mathrm{D}$ & Control using basic mix \\
\hline $\mathrm{E}$ & Control with flow network using \\
& basic mix \\
\hline
\end{tabular}

\subsection{Panel B contents - SMP tendons and flow network}

The concept of crack closure in concrete using SMP tendons is relatively straightforward - a polymer tendon posessing a shape memory effect is embedded in concrete and upon activation it excerts a compressive force as it tries to return to its memorised form. If the tendon crosses a crack the compressive force will result in a reduction in the size of the crack. In the current study the activation of the tendon is achieved by heating it to $90^{\circ} \mathrm{C}$.

The SMP tendons used in the site trial Panel B were $750 \mathrm{~mm}$ long and were manufactured using a custom made rig shown in Figure 8. These tendons were made of 200 polyethylene terephtalate (PET) filaments that were produced in Bradford University, wraped with a heating wire and secured with injection moulded polylactic acid (PLA) sleeves. Additionally two thermocouples, one located on the surface of the filaments and one in the center of the tendon were provided to monitor the temperature during the activation process. The anchorage solution was chosen as a wire rope coupler resting on a mild steel plate on either end of the tendon. In total ten tendons of this size were produced and fitted in the trial panel B and their arrangement can be seen in Figure 9.

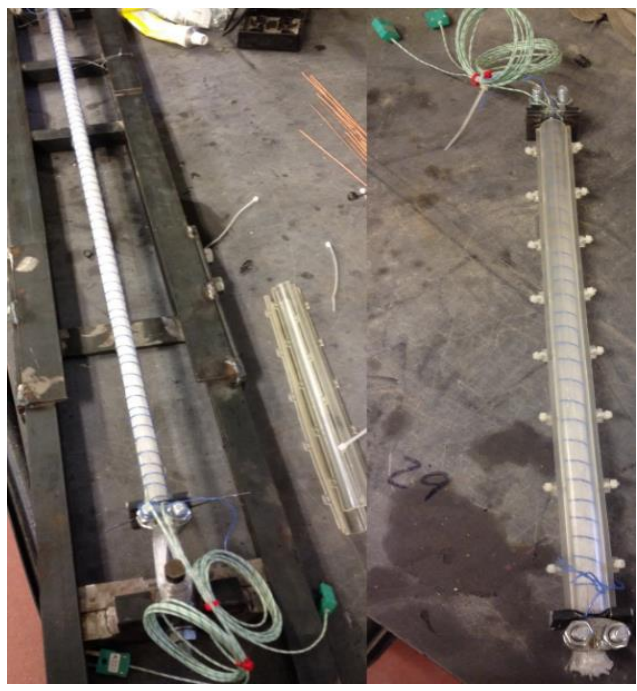

Figure 8: SMP tendon manufacture process left and completed tendon right.

In Panel B the SMP system was coupled with a flow network as shown in Figure 9. The flow network was created using polyurethane tubes with $4 \mathrm{~mm}$ outer diameter that were removed during the demoulding process leaving clear channels in concrete. Custom 3D printed joints were used to ensure the continuity of the network within the panel.

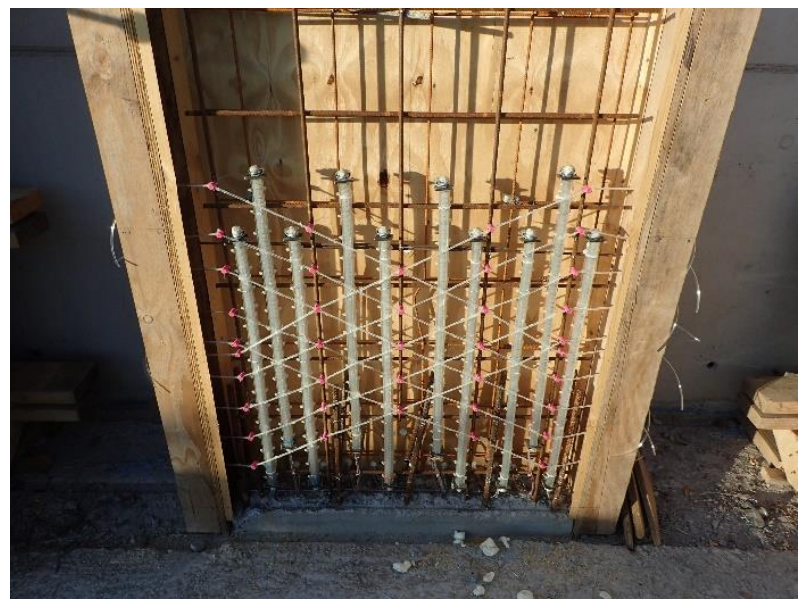

Figure 9: SMP and flow network arrangement fitted in Panel B

A bespoke system was designed and produced to simultaneously activate all ten tendons within the Panel B by heating them to $90^{\circ} \mathrm{C}$. The developed system continuously 
monitored the temperture in each tendon and automatically switched the current on or off to maintain the activation temperature in the tendon. The wired activation system is shown in Figure 10.

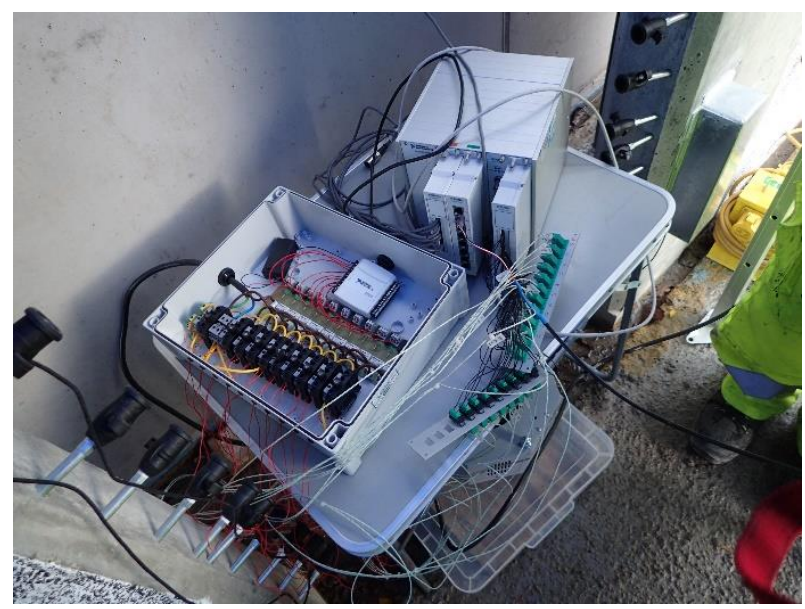

Figure 10: SMP system activation and monitoring setup

\subsection{Testing sequence}

The trial panels were loaded 33 to 36 days after casting in order to induce the crack in the front face. The load was applied until a crack appeared in the expected location (approximately $500 \mathrm{~mm}$ above base). The load was locked off with a nut on the threaded bar and crack width measurements were made via microscope images and DEMEC readings. Afterwards the load was released and the measurements taken again to assess residual crack size. During this process the load, LVDT readings and DIC data was continuously recorded. Additionally permeability and ultrasonic pulse velocity measurements were taken.

After the initial loading phase Panel B underwent an activation and a reloading cycle to assess the effectiveness of the SMP system. Similarly Panel E which was used as a Control for Panel $\mathrm{B}$ underwent a loading and unloading cycle.

Following the initial loading monitoring of the panels was conducted at one month intervals recording microscope images, DEMEC readings and any changes in the LVDT readings.

The use of flow networks in panels B and $\mathrm{E}$ has been planned at 90 days after initial loading.

\section{INITIAL RESULTS}

This section will provide a brief insight into the initial loading results of the trial panels. Other results will be published in due course when they become available.

One of the aims of the M4L project was to scale-up the self-healing techniques for site trials and this has been successfully achieved as evidenced in Figure 11.

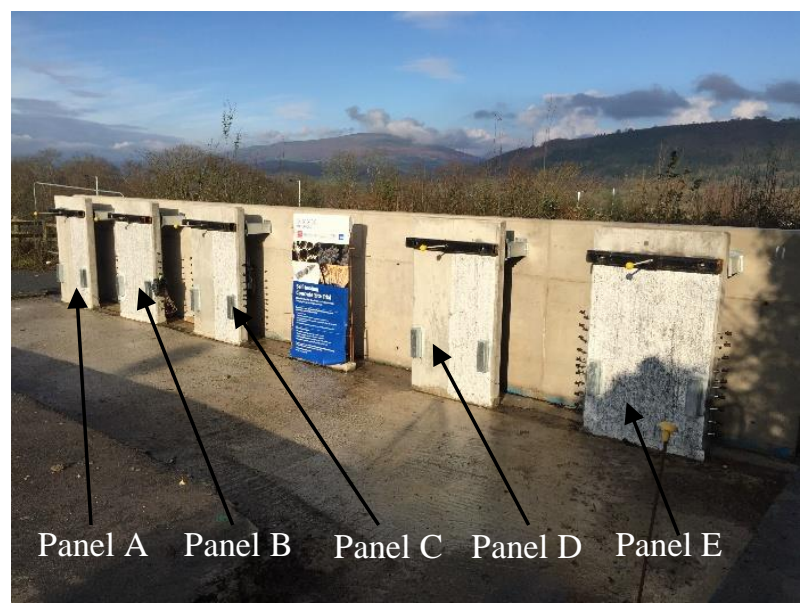

Figure 11: Site trial panels after initial loading

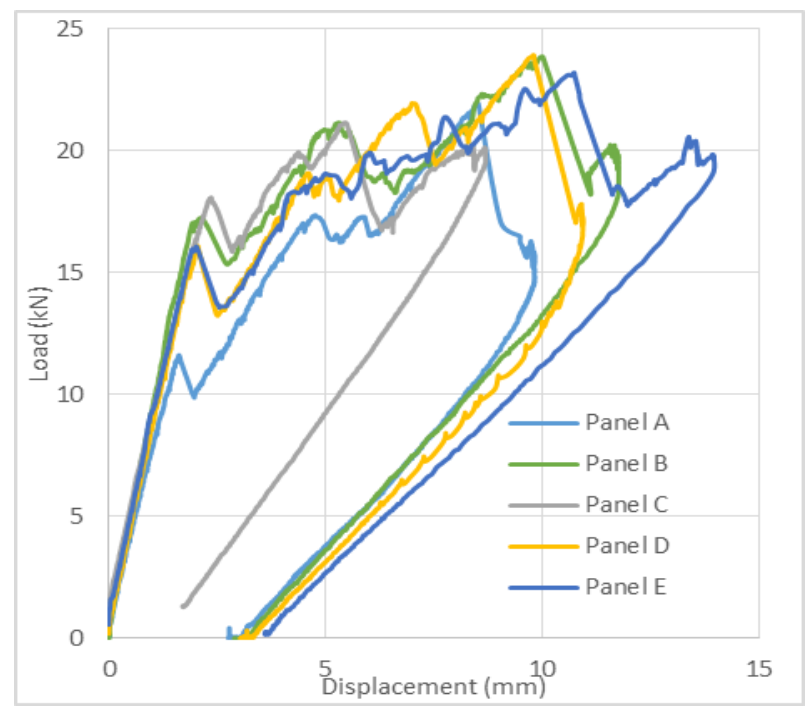

Figure 12: Load versus top of the panel displacement

The load versus the displacement at the top of the panel plot for all panels from the initial loading is shown in Figure 12. During loading, several cracks were formed as can be seen from the load peaks and drops in the graph. The formation of the final crack at the 
expected location, approximately $500 \mathrm{~mm}$ above the base, was achieved with a load ranging from 20 to $25 \mathrm{kN}$.

Figure 13 shows the vertical strain of Panel $B$ after unloading and three cracks can be seen that correspond to the peaks in the load displacement graph. The crack at the expected location is larger than the other ones. Similar cracking behavior and the occurrence of the largest crack at $500 \mathrm{~mm}$ above the base was observed for all panels.

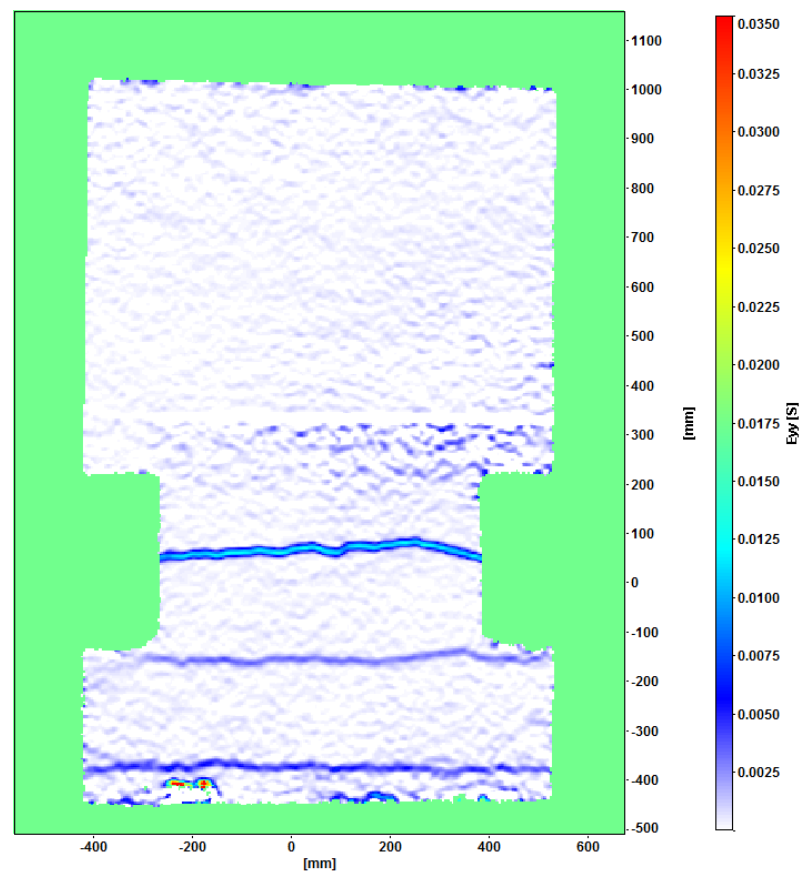

Figure 13: DIC strain plot of Panel B after unloading

The microscope image analysis showed that the residual crack width of the crack $500 \mathrm{~mm}$ above the base for all panels ranged from $0.063 \mathrm{~mm}$ to $0.161 \mathrm{~mm}$.

The site trials are still ongoing and the monitoring is carried out every month. The next site trial event is filling the flow networks with a healing agent and evaluation of the corresponding healing effectiveness.

\section{ENCOUNTERED CHALLENGES}

Undertaking site trials and scaling-up different techniques has been a major task with difficulties accompanying it. A number of factors that are present in site environment but not in laboratory had to be taken into account. This section will provide few examples of the encountered challenges.

Considering the SMP tendon scale-up a custom made rig had to be made to allow their manufacture. Additionally a durable sleeve that would hold the filaments straight and protect the heating wire and thermocouples during casting had to be designed and made. The challenge was to choose a material that could withstand the casting but would not interfere with the tendon activation and crack closure by providing additional reinforcement to the wall panel. Such material was found to be polylactic acid (PLA) which is a polymer with a glass transition temperature of $45-50^{\circ} \mathrm{C}$. This means that above that temperature the polymer becomes soft and is deformable with very little effort thus having a minimal effect on the results.

During the initial laboratory experiments concrete specimens contained single tendons. In order to activate these tendons the specimens were heated as a batch in an oven or with a heating wire but one at a time. Meanwhile for site trials it was preferable to activate all tendons at the same time to prevent twists in the wall. As heating the whole trial panel is not feasible a bespoke system had to be designed, manufactured and tested that could deal with the necessary current, monitor and maintain the required temperature and could be run on site from a generator.

A major factor that had to be taken into account regarding the monitoring equipment was weather conditions. The LVDTs, DIC equipment, load cells, data acquisition hardware, laptops and microscope require electricity. Thus all equipment and connections had to be kept dry to prevent accidents, malfunction and short circuits. Covers were designed and fitted to LVDTs, other equipment during testing and monitoring were positioned under a tent and elevated above the concrete base on tables.

\section{CONCLUSIONS}

The M4L self-healing concrete trials have been successful in achieving their primary aim - scale-up of the healing techniques and their implementation in site trial structure while 
noting the challenges and feasibility in site applications and environment.

Currently the trial panels are being continuously monitored and the next phase of trialing the flow networks has been planned. The results of the ongoing work will be the subject of future publications.

\section{REFERENCES}

[1] De Rooij, M. R. Van Tittelboom, K. De Belie, N. Schlangen, E. 2013. SelfHealing Phenomena in Cement Based Materials. State-of-the-Art Report of RILEM TC 221-SHC.

[2] Lark, R. J. Al-Tabbaa, A. Paine, K.2013 Biomimetic multi-scale damage immunity for construction materials: M4L Project overview, ICSHM 2013, Ghent.

[3] Kanellopoulos, A. Qureshi, T. S. AlTabbaa, A. 2015. Glass encapsulated minerals for self-healing in cement based composites. Construction and Building Materials 98:780-791

[4] Sharma, T. Alazhari, M. Cooper, R. Heath, A. Paine, K. 2015. The Requirements for Autonomic Microbiologically-Induced CalcitePrecipitation in Concrete. ICSHM 2015 Durham, USA.

[5] Pilegis. M, Teall, O. Hazelwood, T. Jefferson, A.D. Gardner, D. Lark, R. 2015. Delayed concrete pre-stressing with shape memory polymer tendons. 'fib Symposium 2015', Copenhagen, Denmark.

[6] Davies, R. Jefferson, A.D. Lark, R. and Gardner, D. 2015. A novel 2D vascular network in cementitious materials. 'fib Symposium 2015', Copenhagen, Denmark.

[7] Davies, R. Pilegis, M, Sharma, T. Kanellopoulos, A. 2015. Materials for Life (M4L): Combining multi-scale healing techniques in cementitious materials. ICSHM 2015 Durham, USA. 